\title{
Geographic distribution and time trends of esophageal cancer in Brazil from 2005 to 2015
}

\author{
CÉSAR AUGUSTO AMORIM ${ }^{1}$, LUCILA PERROTA DE SOUZA ${ }^{1}$, JESSICA P. MOREIRA ${ }^{2}$ \\ RONIR R. LUIZ ${ }^{2}$, ANTONIO JOSÉ DE V. CARNEIRO ${ }^{1}$ and HEITOR S. P. DE SOUZA ${ }^{1,3}$ \\ ${ }^{1}$ Department of Internal Medicine, School of Medicine; ${ }^{2}$ Institute of Public Health Studies, \\ Federal University of Rio de Janeiro, Rio de Janeiro 21941-913; \\ ${ }^{3}$ D'Or Institute for Research and Education (IDOR), Rio de Janeiro 22281-100, Brazil
}

Received December 18, 2018; Accepted April 5, 2019

DOI: $10.3892 / \mathrm{mco} .2019 .1842$

\begin{abstract}
The purpose of the present study was to investigate the geographical distribution and time trends of the incidence and lethality of esophageal cancer (EC) in Brazil. The present study conducted an ecological study of EC using records from January 2005 to December 2015 in the Health Informatics Department of the Brazilian Ministry of Health (DATASUS) registry. In addition to demographical data on the population, EC incidence and lethality rates were estimated from hospitalizations and in-hospital mortalities and were adjusted by total available hospital beds. The adjusted EC rates per 100,000 increased from 9.1 in 2005 to 12.1 in 2015. The prevalence among males increased from 69 to $78 \%$, while the female rates remained stable over the same period. Although EC was the most common in South and Southeast Brazil, the rates increased proportionately more in the other regions of the country, especially among males. Geographical analysis revealed higher rates of EC in more urbanized areas, with a coast-to-inland gradient. While rates increased in people older than 50 years, they decreased among people below this age. However, the lethality rates remained stable and high during the study period, overlapping with hospital admission rates. The recent increasing trend in the EC incidence, with shifts from the south towards the north and from more urbanized towards rural areas, suggests that environmental factors are crucial in EC pathogenesis. The concentration of EC in South Brazil may reflect the presence of major environmental factors in association with a possible genetic predisposition. The unchanging high mortality associated with EC in the rapidly
\end{abstract}

Correspondence to: Professor Heitor S. P. de Souza, Department of Internal Medicine, School of Medicine, Federal University of Rio de Janeiro, Rua Prof. Rodolpho Paulo Rocco 255, Ilha do Fundão, Rio de Janeiro 21941-913, Brazil

E-mail: hsouza@hucff.ufrj.br

Key words: esophageal cancer, ecological study, hospitalization rates, lethality rates, time trend analysis aging population suggests that EC will continue to impose a significant social and economic burden in the future.

\section{Introduction}

Recent estimates indicate that esophageal cancer (EC) affects approximately half a million people worldwide, and its incidence continues to increase $(1,2)$. Currently, EC is the eighth most common incident cancer in the world and has been characterized by its poor survival rate $(3,4)$. Although esophageal carcinogenesis has not been fully elucidated, EC is thought to result from complex interactions between host and environmental elements (5).

While some risk factors for EC have already been recognized, they may have some peculiarities depending on the major subtype: Squamous cell carcinoma (ESCC) or adenocarcinoma (EAC). More common in males than in females and among blacks than among whites in the United States, ESCC has been consistently associated with smoking and alcohol consumption. In contrast, EAC is 8-fold more common among males and 5-fold more common in whites than in blacks in the United States (6). Although tobacco is also a known risk factor for EAC (7), chronic gastroesophageal reflux disease (GERD) is believed to represent the most important underlying mechanism, either directly or through the induction of a preneoplastic lesion, which is known as Barrett's esophagus. Notably, the increased incidence of GERD and Barrett's esophagus in the last few decades has been correlated with an increased incidence of EAC in the Western population $(8,9)$. Obesity has also been implicated in the increased risk for EAC $(10,11)$, either through the association with GERD or through inflammatory mediators produced by adipocytes (6).

Although ESCC predominates worldwide, recent data from Western European countries, the United States and Australia point to a marked increase in the EAC subtype (2). In contrast, ESCC continues to represent the most common type of EC in South America and in the 'Asian esophageal cancer belt' (12). Indeed, in some areas in China, the ESCC incidence reached more than 100 cases per 100,000 person-years $(13,14)$.

Further investigating the etiopathogenesis, including the epigenetic modifications involved in esophageal carcinogenesis $(15,16)$, will be fundamental for explaining the increase 
in EC (17) and for unveiling underlying mechanisms that may impact future therapies for EC. Meanwhile, understanding the epidemiology of EC will hopefully be the key to elucidating risk factors and potential causes and may become the cornerstone of preventive strategies. Therefore, the aim of this study was to analyze the geographic distributions and time trends of the EC incidence and lethality in Brazil to identify areas with differential risks and outcomes of EC.

\section{Materials and methods}

Data source. The study methods have been described in similar previous studies from our group elsewhere $(18,19)$. Data from the Health Informatics Department of the Brazilian Ministry of Health (DATASUS) (http://www2.datasus.gov. br/DATASUS) were retrospectively searched for patients with the International Statistical Classification of Diseases and Related Health Problems, Tenth Revision code of EC (ICD-10 code: C15.0 to C15.9). This population-based health and disease registry includes information such as medical procedures, hospital admission and discharge, mortality, and demographic data, covering approximately the entire population. Hospital discharge records were used to estimate the EC incidence. All data is anonymous archival data that does not allow for the identification of individual subjects; therefore, the requirement for ethical approval was waived. We assumed that hospital-based procedures for either EC diagnosis or treatment would reflect the actual disease numbers.

Study design, population, and variables. We performed an ecological study using the DATASUS registry and searched for the most recent and consistent information containing complete data entries of hospitalizations due to EC. Ecological studies allow geographic and temporal analyses of risk factors potentially involved in the development of diseases in a given population. We analyzed all cases from January 2005 to December 2015 for which a diagnosis of EC was assigned. The period of study was defined according to the most consistent data available in recent years. The data included the town of residence during hospital admission and death, and patients were categorized by gender and age; for the latter category, individuals were stratified as $<20$ years, 20-49 years, 50-69 years, and $>70$ years of age. Standardized rates regarding the incidence (the rate of new hospital admissions for EC) and lethality (the capacity of EC to cause intra-hospital death) were estimated from hospitalizations. For the geographic distribution analysis, EC hospitalization rates were obtained per 100,000 inhabitants in the individual municipalities.

Statistical analysis. Exploratory procedures with a quantitative approach were applied to the data using IBM SPSS software for Windows (Version 20, SPSS Inc.). Summary descriptive statistics and graphical displays were generated by Tabwin 3.2 (Tab for Windows 3.2, free software that allows organization of multiple applications into grouped tabs, available at http://www2.datasus.gov.br/DATASUS). EC hospitalization rates were adjusted by the available hospital beds in Brazil in the study period. Estimates of resident populations were obtained from Instituto Brasileiro de Geografia e Estatística (IBGE; Brazilian Institute of Geography and Statistics) projections. Linear regression was applied to evaluate temporal trends in the EC incidence and lethality by sex using Microsoft Excel Software (Microsoft Excel for Mac 2011, Version 14.4.9, 2010; Microsoft Corporation).

\section{Results}

Hospitalizations for EC. The total numbers of hospitalizations for EC were 12,641 in 2005 and 17,792 in 2015, 1935 and 2966 of which ended in death, respectively. Adjusted rates according to available hospital beds (Fig. S1) increased from 9.1 in 2005 to 12.1 in 2015 per 100,000 inhabitants. Regarding gender, EC rates were consistent with the world trend for male predominance, which were $69 \%$ in 2005 and $78 \%$ in 2015. In fact, in males, hospitalization rates for EC per 100,000 inhabitants increased from 12.8 to 19.1 , while female rates remained stable during the period (Fig. 1).

Next, we analyzed the distribution of EC according to the age at diagnosis using age-standardized rates of hospitalizations. Very few cases were observed below the age of 20 years; therefore, the data are not shown (Fig. 2). Relatively low rates of EC were detected within the population below 50 years of age. In this age group, both male and female hospitalization rates fell from 2005 to 2015, especially among females for whom rates decreased more than 3-fold. In the age range of 50-69 years, we observed an increase of approximately $32 \%$ among males in contrast to a decrease of almost $5 \%$ among females. Above the age of 70, we detected an increase of approximately $20 \%$ among females (Fig. 2A) and an increase of more than $35 \%$ among males (Fig. 2B) in the same period.

Lethality rates from EC. Regarding EC-associated lethality, considering gender, rates remained relatively stable during the period analyzed (Fig. 3).

The age-standardized analysis revealed that lethality among males also remained stable over the 11-year period, with only a slight increase in cases below 50 years of age (12\% in 2005 and $16 \%$ in 2015) (Fig. 4A). Among females under 50 years of age, the rate increased from 5\% in 2005 to $15 \%$ in 2015 (Fig. 4B). In both genders, a slightly increased lethality rate was observed among people over 70 years old.

Geographic distribution of EC. During the study period, an overall 33\% increase in estimated EC rates in Brazil was noted, which was mainly driven by men aged 50 to 69 years $(+32 \%)$ and both men and women aged 70 years or older $(+36$ and $+20 \%$, respectively). Marked increases in EC rates were observed in all five major regions of the country, particularly in the Central-West region with an increase of $61 \%$ in the period. The Southeast, Northeast and North regions also showed notable increases (51, 51 and $48 \%$, respectively), while the South region had the lowest increase (35\%).

Because of the economic and demographic disparities of Brazil, we utilized a model that classifies municipalities according to population and demographic density as rural small $(<50,000$ or $<80$ inhabitants $/ \mathrm{km})$, rural medium ( $\geq 50,000$ or $\geq 80$ inhabitants $/ \mathrm{km}$, even if the population is $<50,000$ inhabitants), and true urban centers ( $>100,000$ inhabitants) (20). To analyze the trend of the Brazilian population 


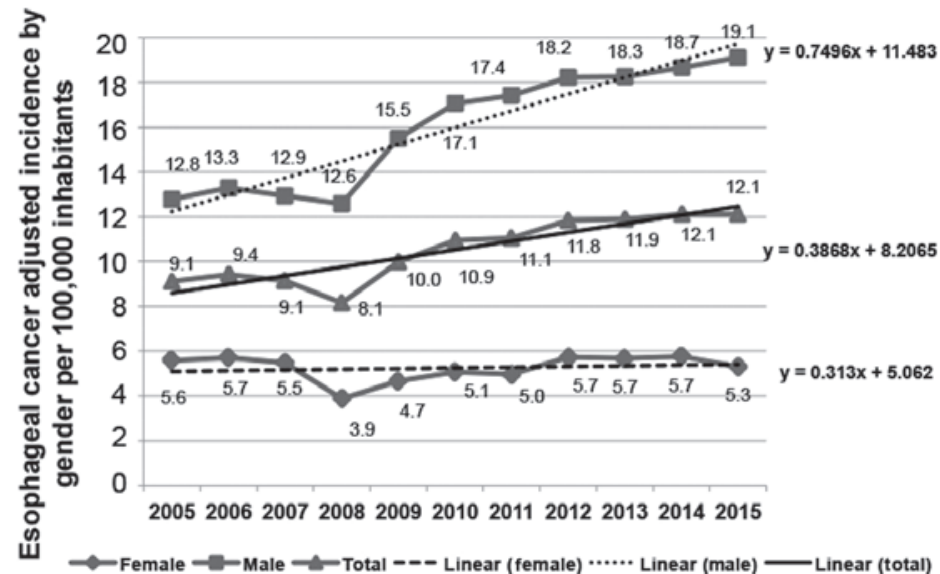

Figure 1. Esophageal cancer incidence rates by gender, estimated from hospitalizations in Brazil from 2005 to 2015.
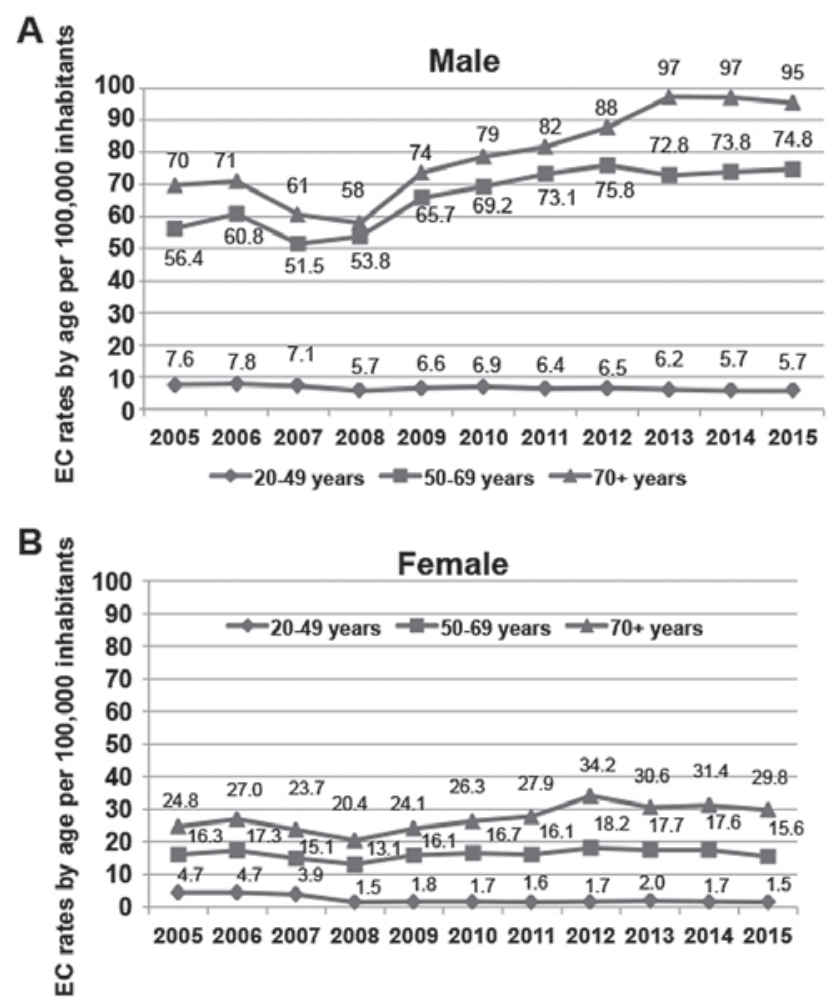

Figure 2. Age-standardized EC incidence rates by gender, estimated from hospitalizations in Brazil from 2005-2015. (A) Male and (B) female. EC, esophageal cancer.

to congregate in large urban centers, EC incidence and lethality rate data were collected considering municipality size and relations to metropolitan regions. Large municipalities comprise $86 \%$ of the metropolitan-integrated population. Municipalities integrated or not integrated into metropolitan regions had increases in the EC incidence of 24 and $39 \%$, respectively, between 2005 and 2015. In this period, we observed increases in EC in small municipalities integrated (127\%) and in large municipalities not integrated (131\%) into metropolitan regions. Regarding the lethality rate, the most notable increases were observed in medium and large municipalities not integrated into metropolitan regions (14 and $17 \%$, respectively; Table I).

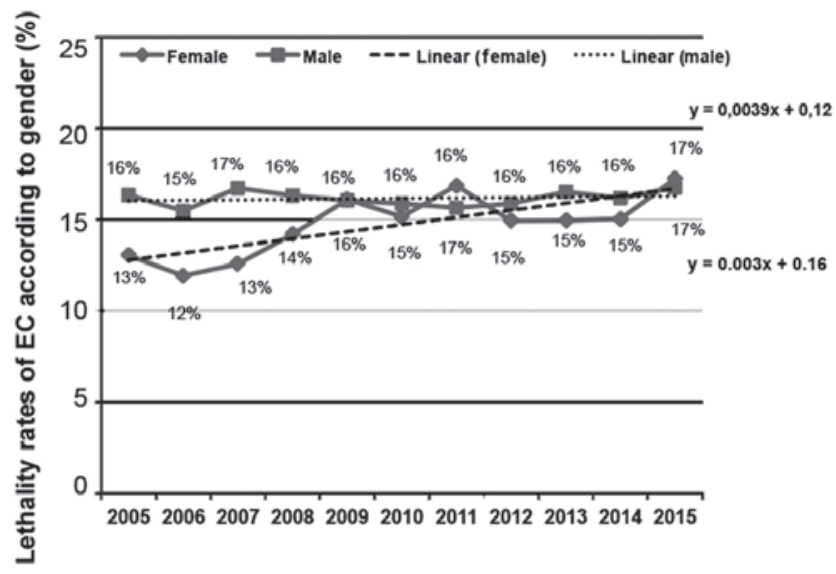

Figure 3. EC lethality rates (\%) by sex, estimated from in-hospital deaths in Brazil from 2005 to 2015. EC, Esophageal cancer.

Municipal rates of hospitalization and in-hospital death for EC were calculated per 100,000 inhabitants and were plotted on maps per major region in the years 2005 and 2015 and are shown in Figs. S2 and S3 in the appendices.

\section{Discussion}

The results of the present study indicate that the EC incidence has increased, while the lethality rate has remained stable from 2005 to 2015 in Brazil. In addition to the male predominance in EC, we observed an increase among individuals older than fifty years in contrast to a decrease among individuals under fifty years of age. The geographic distribution of EC demonstrated a higher concentration in the South region but also revealed a greater relative increase across the other regions of the country.

The considerable discrepancies in the worldwide EC incidence (1) are probably because ESCC and EAC are associated with different risk factors. EC is estimated to occur 3-4-times more often in males $(1,5)$, and the difference is more marked for EAC for which sex ratios (M:F) range, for example, from 5:1 in France to 10:1 in the United Kingdom (21,22). A rapid increase in EAC among males was also observed in the United States in the last four decades (23). Here, we found an 


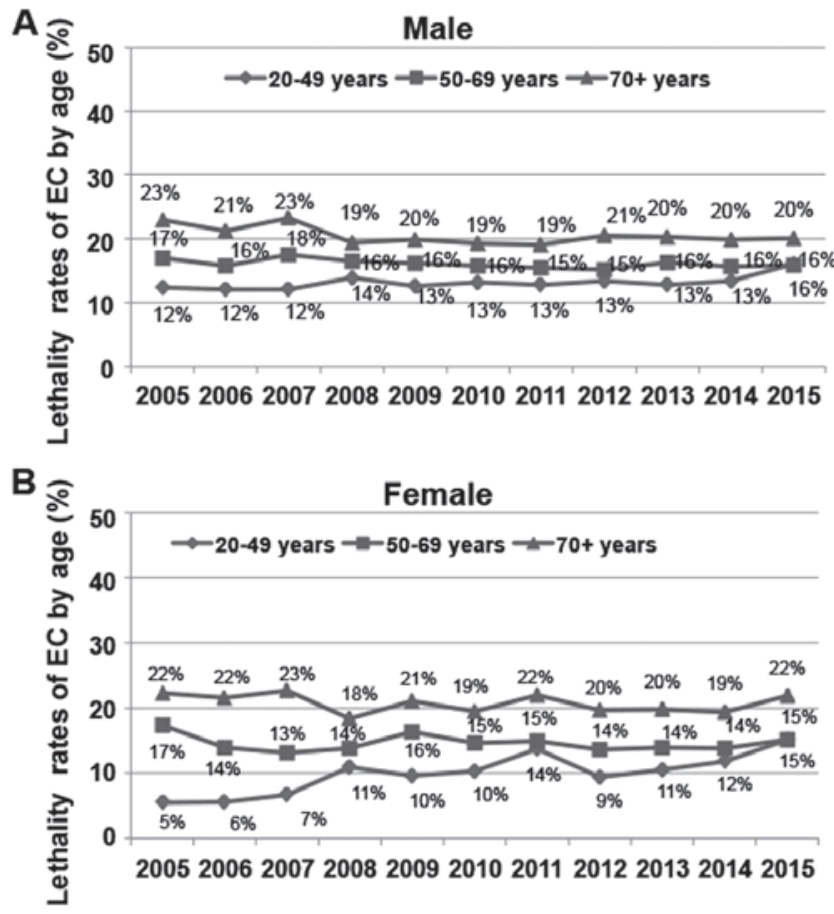

Figure 4. Age-standardized EC lethality rates (\%) by sex, estimated from in-hospital deaths in Brazil from 2005 to 2015. (A) Male and (B) female. EC, esophageal cancer.

average ratio of 3.6:1 (M:F), which is more compatible with the predominance of the ESCC subtype. The male propensity may be attributed to the greater concomitant exposure to the main risk factors for EC, including tobacco and alcohol (24). In contrast, gastroesophageal reflux disease and obesity, which are important risk factors for EAC, do not justify the disproportionate gender bias towards men (25). Currently, almost one in five Brazilians are considered obese (26). However, similar to data from European countries and the United States, trends for the EC incidence, including EAC, do not match corresponding trends in obesity (27). While the reasons for male predominance in EC remain incompletely understood, a role of androgens and androgen receptors has been recently suggested $(28,29)$.

The gradual increase in EC should be further analyzed considering the sociodemographic changes and inequalities among the municipalities and regions of the country. Large metropolitan municipalities and the highest development indices are usually associated with the South and Southeast regions. In this sense, in addition to smoking and alcohol, other factors, including obesity, high consumption of processed foods, low fiber intake, the aging population, improvement in the human development index (HDI), and the Human Inequality Coefficient (30-33), may be operating in concert to cause changes in EC epidemiology. Interestingly, other studies had already identified South and Southeast Brazil as regions with higher frequencies of cancer cases $(34,35)$. Similar to recent ecological studies from our group pertaining to gastric cancer (18) and pancreatic cancer (19), the hospitalization rates were higher in the South and Southeast regions, whereas in the North and Northeast regions, the rates were the lowest in the country. Here, the highest rates of EC were observed in areas of greater economic development, which also have a higher HDI and lower social vulnerability indices (SVIs). Although the highest EC rates in Brazil were found in the South and Southeast regions, the greatest increase occurred in the Central-West region, followed by the North and Northeast regions. Although indices of social development usually identify multiple deprivations in North and Northeast Brazil, these regions exhibited the greatest advances in the last two decades as the HDI increased $36.4 \%$ and the SVI decreased 27\% between 2000 and 2010 (32,33). Moreover, the gross product of the Northeast increased 3\% in 2012, which is greater than three-fold compared to the national average (36). Socioeconomic development may have allowed better access to health services and improvements in facilities, affecting the quality of diagnosis, documentation, and treatment in general. This development may also justify the largest increases in EC rates within small metropolitan cities and large cities in nonmetropolitan regions.

The time trends of the age-stratified groups show an increased EC incidence among males aged 50 years or more, a phenomenon usually attributed to accumulated environmental exposure $(37,38)$. This finding suggests that exposure to risk factors for EC probably differed between male and female patients. Here, we noted a marked increase in EC among males in the age groups above 50 years, while among females, we noted only a small increase in the age group over 70 years. The overall tendency for increases apparently accompanies the increased longevity observed in the country. Recent data indicate that Brazil has the sixth oldest population in the world, with an increase of approximately 500\% in the last four decades $(39,40)$. In addition, the relative decrease in EC rates among people under 50 years may reflect a more recent reduction in environmental exposure, such as smoking. Although the country's population is progressively growing older, changes were not relevant in the relatively short period analyzed in this study. Moreover, the subgroup analyses including age-standardized and gender incidences used rates considering relative differences within each municipality unit. Thus, changes in the EC incidence have been considered to be probably related to the different municipalities characterized by specific environments and individual particularities.

Smoking, one of the most important factors related to EC, has dropped almost $30 \%$ in the last decade in Brazil, and rates are higher among men (14.4\%) than among women $(8.6 \%)(41,42)$. Moreover, smoking is more prevalent in the South and Southeast regions where the highest rates of EC are also observed (41). Actually, the highest smoking frequencies in the country are located in two large metropolises in South Brazil: Porto Alegre, 25.2\% and Curitiba, 21.5\% (41,43). Notably, Brazil is currently one of the largest tobacco producers in the world, and the South region accounts for $98 \%$ of the country's tobacco farms $(44,45)$. In particular, Brazilian tobacco farmers show a higher frequency of smoking (31\%) than the rural male population as a whole (46). Some other lifestyle factors, however, may also act directly on the esophagus and be implicated in EC. For instance, ethanol consumption, especially together with smoking, is also a well-recognized factor related to EC. For example, recently, the abusive consumption of alcoholic beverages in Brazil was determined to be $19.1 \%$ on average and was greater among males (47). Interestingly, the 


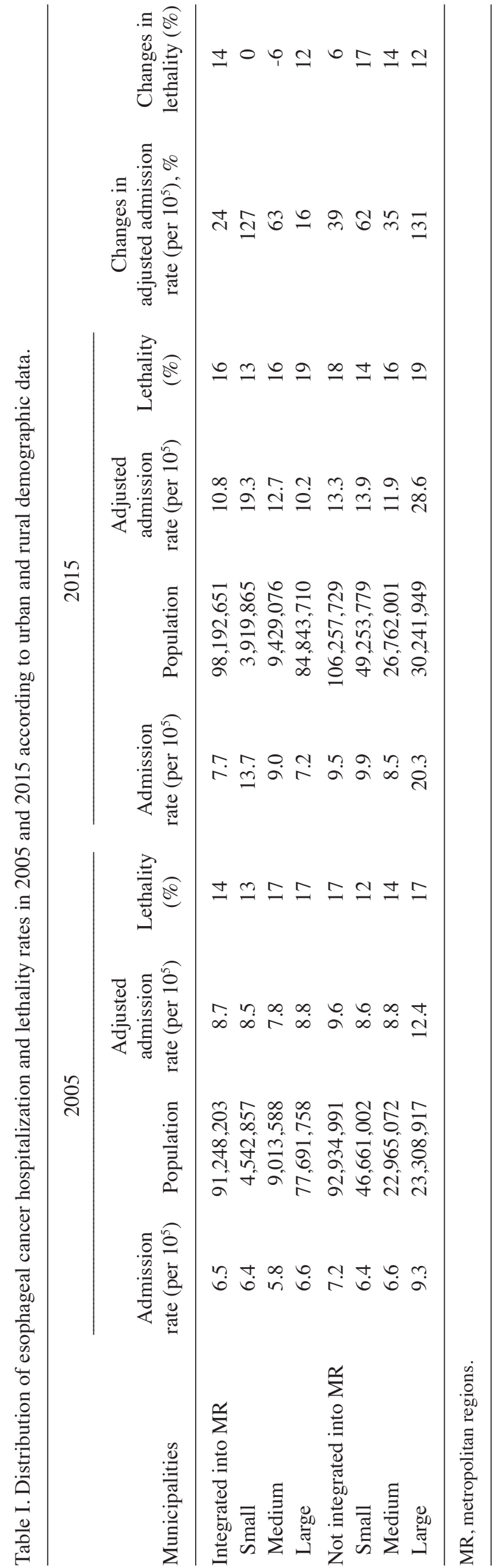

traditional habit of drinking mate, a kind of hot tea, has been proposed as an additional explanation for the concentration of EC in the South region of the country (48-50). Hot mate tea has been associated with different patterns of TP53 mutations, probably due to epigenetic modifications driven by chronic hyperthermic irritation (51). However, concomitant exposure to other various lifestyle risk factors, including ethanol, tobacco, charcoal-grilled red meat and animal fat, and the low consumption of fruits and vegetables (52), may render the influence of mate difficult to interpret. Moreover, the potential roles of other elements associated with low living standards still present in several Brazilian municipalities should be considered, such as poor oral hygiene and nutrition, which are also linked to oral and pharyngeal cancer (53).

The highest EC rates observed in the South region should also be analyzed in the context of specific population features. The Brazilian population is regarded as one of the most heterogeneous in the world due to five centuries of crossings among distinct ethnic origins (54). The genetic background of the population shows a wide range and variable patterns of admixture, with a major contribution of European ancestry, followed by African and Amerindian contributions (55). In a recent study, investigators demonstrated the prevalence of the European ancestry among urban populations, which reached almost $80 \%$ in the South region versus less than $60 \%$ in the North, Northeast, and Central-West regions, increasing along a north-to-south gradient (56) and corroborating the notion that the genetic heterogeneity in Brazil is mostly detected among regions rather than within regions (57). While the incidence of ESCC is reported to be three-times higher in blacks (58), EAC is markedly more common in whites $(58,59)$. In a recent study on EC in Sao Paulo, Southeast Brazil, with more than five hundred cases, investigators found marked predominance rates of both ESCC and EAC among white patients (60). These findings are in agreement with other international studies showing increased incidence rates among whites and may reflect the local predominance of European ancestry as observed throughout South Brazil. Although the methodology of this study does not allow distinction between the major subtypes of EC, the disproportionately high concentrations observed in the Southeast region and particularly in the South region may reflect local ongoing increases in EAC. Notably, Brazil is a continental country with substantial demographic and developmental inequalities throughout its more than five thousand municipalities. In fact, the country is extremely heterogeneous in several aspects, including urbanization, population densities, climate, economy, and industrialization, in addition to cultural, dietary, and even genetic particularities. Thus, the increase in EC rates in Brazil may have been fueled by the acquisition of risk factors typical of modern societies in the last few decades (such as dietary changes and smoking patterns) along with other elements, including industrialization, improvement in the HDI, and the Human Inequality Coefficient.

EC represents a serious malignancy since its incidence continues to increase while its prognosis and mortality rate remain practically unchanged $(61,62)$. EC is usually associated with a very poor survival rate, and the geographic distribution of mortality is similar to that of its incidence, with the highest rates per 100,000 inhabitants occurring in 
East Asia (14.1) and Southern Africa (12.8) in men and in Eastern (7.3) and Southern Africa (6.2) in women. In this study, we observed a small increase in lethality in females and a relatively stable trend among males. These trends were maintained fairly well in the analysis by age-standardized groups and are also consistent with previous reports $(1,63)$. Despite improvements in diagnosis, including the availability of endoscopy, the mortality rate remains unacceptably high in most countries (64). Nonetheless, reports showing reductions in mortality rates in some countries have been attributed to better surgical results. As surgical treatment represents the best potentially curative option for EC, improved outcomes reflect an increasing number of surgeries in high-volume centers and the implementation of multimodal therapy $(65,66)$.

Although the results of this study may allow initial insight into EC behavior and time trends in Brazil due to the collection of information from all 5565 municipalities and the time trend analysis of EC in the country for the first time, some limitations need to be addressed. First, using the available DATASUS database, distinguishing between ESCC and $\mathrm{EAC}$, the two major types of tumors, is impossible given their epidemiological peculiarities. Second, the system does not allow evaluation of information regarding co-morbidities and therapy. Third, differences in the availability and quality of health care in less developed areas of the country may result in potential discrepancies in the available data. Fourth, the analysis based on hospitalization records does not consider outpatients who had not been subjected to medical procedures or hospital admissions. Fifth, the concept of a municipality is probably different in Brazil from that in most countries. In this regard, in addition to geographic heterogeneities, Brazilian cities may show discrepancies in terms of population, with huge differences in densities. Nevertheless, such differences would be regarded as municipal units of the same level in our database. Therefore, considering all these limitations together, the results of this study must be interpreted with caution. Despite the potential limitations of this study, all procedures were rigorously carried out to produce a database containing nationwide information gathered in a single electronic system.

The recent increase in the EC incidence in Brazil follows a global tendency and is concentrated in the population above seventy years of age. Although the current higher rates in the South and Southeast regions may reflect the presence of major environmental factors in association with a possible genetic predisposition, shifts in the incidence from the south towards the north and from urbanized to rural areas have been observed. Such geographic shifts in addition to the relative decrease in EC among individuals under the age of fifty years support the notion of ongoing dynamic changes within the socioeconomic environment. However, the unchanging high mortality associated with EC, along with the rapidly aging population, suggests that EC will remain a critical health issue in Brazil in the near future, potentially imposing significant social and economic burdens.

\section{Acknowledgements}

The authors would like to thank the Brazilian Research Foundations CNPq and FAPERJ for their financial support.

\section{Funding}

This work was supported by grants from the Brazilian Research Council (CNPq; grant no. 302401/2016-4) and the Fundação Carlos Chagas Filho de Amparo à Pesquisa do Estado do Rio de Janeiro (grant no. E26/202.781/2017).

\section{Availability of data and materials}

The datasets analyzed during the current study are available in the Health Informatics Department of the Brazilian Ministry of Health (DATASUS) repository (www2.datasus. gov.br/DATASUS). DATASUS registries include hospital admission and discharge information, medical procedures and mortality, reference tables and demographic data (age, sex, municipality) collected by the Instituto Brasileiro de Geografia e Estatística (Brazilian Institute of Geography and Statistics).

\section{Authors' contributions}

CAA and LPdS participated in the conception and design of the study, the acquisition, analysis and interpretation of data, and the drafting of the manuscript. JPM and RRL participated in the acquisition, analysis and interpretation of the data, and the drafting of parts of the manuscript. AJC and HSPdS participated in the conception and design of the study, obtained funding, analyzed and interpreted the data, and critically revised the manuscript for important intellectual content. All authors gave final approval of the submitted version of the manuscript.

\section{Ethics approval and consent to participate}

Not applicable.

\section{Patient consent for publication}

Not applicable.

\section{Competing interests}

The authors declare that they have no competing interests.

\section{References}

1. Jemal A, Bray F, Center MM, Ferlay J, Ward E and Forman D: Global cancer statistics. CA Cancer J Clin 61: 69-90, 2011.

2. Pennathur A, Gibson MK, Jobe BA and Luketich JD: Oesophageal carcinoma. Lancet 381: 400-412, 2013.

3. Mao WM, Zheng WH and Ling ZQ: Epidemiologic risk factors for esophageal cancer development. Asian Pac J Cancer Prev 12: 2461-2466, 2011.

4. Enzinger PC and Mayer RJ: Esophageal cancer. N Engl J Med 349: 2241-2252, 2003.

5. Domper Arnal MJ, Ferrandez Arenas A and Lanas Arbeloa A: Esophageal cancer: Risk factors, screening and endoscopic treatment in western and eastern countries. World J Gastroenterol 21: 7933-7943, 2015

6. Wheeler JB and Reed CE: Epidemiology of esophageal cancer. Surg Clin North Am 92: 1077-1087, 2012

7. Oze I, Matsuo K, Ito H, Wakai K, Nagata C, Mizoue T, Tanaka K Tsuji I, Tamakoshi A, Sasazuki S, et al: Cigarette smoking and esophageal cancer risk: An evaluation based on a systematic review of epidemiologic evidence among the Japanese population. Jpn J Clin Oncol 42: 63-73, 2012. 
8. Yousef F, Cardwell C, Cantwell MM, Galway K, Johnston BT and Murray L: The incidence of esophageal cancer and high-grade dysplasia in Barrett's esophagus: A systematic review and meta-analysis. Am J Epidemiol 168: 237-249, 2008.

9. Bhat S, Coleman HG, Yousef F, Johnston BT, McManus DT, Gavin AT and Murray LJ: Risk of malignant progression in Barrett's esophagus patients: Results from a large population-based study. J Natl Cancer Inst 103: 1049-1057, 2011.

10. Renehan AG, Tyson M, Egger M, Heller RF and Zwahlen M: Body-mass index and incidence of cancer: A systematic review and meta-analysis of prospective observational studies. Lancet 371: 569-578, 2008

11. Hoyo C, Cook MB, Kamangar F, Freedman ND, Whiteman DC, Bernstein L, Brown LM, Risch HA, Ye W, Sharp L, et al: Body mass index in relation to oesophageal and oesophagogastric junction adenocarcinomas: A pooled analysis from the International BEACON Consortium. Int J Epidemiol 41: 1706-1718, 2012.

12. Reed PI and Johnston BJ: The changing incidence of oesophageal cancer. Endoscopy 25: 606-608, 1993.

13. Tran GD, Sun XD, Abnet CC, Fan JH, Dawsey SM, Dong ZW, Mark SD, Qiao YL and Taylor PR: Prospective study of risk factors for esophageal and gastric cancers in the linxian general population trial cohort in China. Int J Cancer 113: 456-463, 2005.

14. Munoz N, Crespi M, Grassi A, Qing WG, Qiong S and Cai LZ: Precursor lesions of oesophageal cancer in high-risk populations in Iran and china. Lancet 1: 876-879, 1982.

15. Kaz AM and Grady WM: Epigenetic biomarkers in esophageal cancer. Cancer Lett 342: 193-199, 2014

16. Das M, Saikia BJ, Sharma SK, Sekhon GS, Mahanta J and Phukan RK: p16 hypermethylation: A biomarker for increased esophageal cancer susceptibility in high incidence region of North East India. Tumour Biol 36: 1627-1642, 2015.

17. Lepage C, Rachet B, Jooste V, Faivre J and Coleman MP: Continuing rapid increase in esophageal adenocarcinoma in England and Wales. Am J Gastroenterol 103: 2694-2699, 2008.

18. Amorim CA, Moreira JP, Rial L, Carneiro AJ, Fogaça HS Elia C, Luiz RR and de Souza HS: Ecological study of gastric cancer in Brazil: Geographic and time trend analysis. World J Gastroenterol 20: 5036-5044, 2014.

19. Perrotta de Souza LM, Moreira JPL, Fogaca HS, Luiz RR and de Souza HS: Pancreatic cancer incidence and lethality rates in Brazil: An ecological study. Pancreas 46: 699-706, 2017.

20. Veiga JE: The rural dimension of Brasil. Estud Soc Agric 12: 71-94, 2004

21. Lepage C, Drouillard A, Jouve JL and Faivre J: Epidemiology and risk factors for oesophageal adenocarcinoma. Dig Liver Dis 45: 625-629, 2013

22. Thrift AP and Whiteman DC: The incidence of esophagea adenocarcinoma continues to rise: Analysis of period and birth cohort effects on recent trends. Ann Oncol 23: 3155-3162, 2012.

23. Mathieu LN, Kanarek NF, Tsai HL, Rudin CM and Brock MV: Age and sex differences in the incidence of esophageal adenocarcinoma: Results from the surveillance, epidemiology, and end results (SEER) registry (1973-2008). Dis Esophagus 27: 757-763, 2014.

24. Lindblad M, Ye W, Lindgren A and Lagergren J: Disparities in the classification of esophageal and cardia adenocarcinomas and their influence on reported incidence rates. Ann Surg 243: 479-485, 2006

25. Whiteman DC, Sadeghi S, Pandeya N, Smithers BM, Gotley DC, Bain CJ, Webb PM and Green AC; Australian Cancer Study: Combined effects of obesity, acid reflux and smoking on the risk of adenocarcinomas of the oesophagus. Gut 57: 173-180, 2008.

26. Souza L, Brunken GS, Segri NJ and Malta DC: Trends of self-rated health in relation to overweight in the adult population in Brazilian midwest capitals. Rev Bras Epidemiol 20: 299-309, 2017.

27. Kroep S, Lansdorp-Vogelaar I, Rubenstein JH, Lemmens VE, van Heijningen EB, Aragonés N, van Ballegooijen M and Inadomi JM: Comparing trends in esophageal adenocarcinoma incidence and lifestyle factors between the united states, Spain, and the Netherlands. Am J Gastroenterol 109: 336-343; quiz 335, $344,2014$.

28. Sukocheva OA, Li B, Due SL, Hussey DJ and Watson DI: Androgens and esophageal cancer: What do we know? World J Gastroenterol 21: 6146-6156, 2015.

29. Lagergren K, Lagergren J and Brusselaers N: Hormone replacement therapy and oral contraceptives and risk of oesophageal adenocarcinoma: A systematic review and meta-analysis. Int J Cancer 135: 2183-2190, 2014
30. Szwarcwald CL, Bastos FI, Barcellos C, Pina MF and Esteves MA: Health conditions and residential concentration of poverty: A study in Rio de Janeiro, Brazil. J Epidemiol Community Health 54: 530-536, 2000.

31. Bortz M, Kano M, Ramroth H, Barcellos C, Weaver SR, Rothenberg R and Magalhães M: Disaggregating health inequalities within Rio de Janeiro, Brazil, 2002-2010, by applying an urban health inequality index. Cad Saude Publica 31 (Suppl 1): S107-S119, 2015

32. United Nations Development Programme: Human development indices and indicators: 2018 statistical update. http://hdr.undp. org/en/content/human-development-indices-indicators-2018-statistical-update. Accessed November 5, 2018.

33. United Nations Educational, Scientific and Cultural Organization: United Nations Educational SaCO: Institute for statistics. http:// www.unesco.org/new/en/santiago/resources/statistics/. Accessed November 5, 2018.

34. Lin CC, Chiang JH, Li CI, Liu CS, Lin WY, Hsieh TF and Li TC: Cancer risks among patients with type 2 diabetes: A 10-year follow-up study of a nationwide population-based cohort in Taiwan. BMC cancer 14: 381, 2014.

35. Pinto FG and Curi PR: Mortality due to neoplasms in Brazil (1980/1983/1985): Grouping by states, behavior and trends. Rev Saude Publica 25: 276-281, 1991 (In Portuguese).

36. Instituto Brasileiro de Geografia e Estatistica (IBGE): Health statistics: Survey of medical-sanitary assistance 2009. https:// ww2.ibge.gov.br/english/estatistica/populacao/condicaodevida/ ams/2009/default.shtm. Accessed November 5, 2018.

37. Zhang Y: Epidemiology of esophageal cancer. World J Gastroenterol 19: 5598-5606, 2013.

38. Muwonge R, Ramadas K, Sankila R, Thara S, Thomas G, Vinoda J and Sankaranarayanan R: Role of tobacco smoking, chewing and alcohol drinking in the risk of oral cancer in Trivandrum, India: A nested case-control design using incident cancer cases. Oral Oncol 44: 446-454, 2008.

39. Paim J, Travassos C, Almeida C, Bahia L and Macinko J: The Brazilian health system: History, advances, and challenges. Lancet 377: 1778-1797, 2011.

40. Beard JR and Bloom DE: Towards a comprehensive public health response to population ageing. Lancet 385: 658-661,2015.

41. Malta DC, Stopa SR, Santos MAS, Andrade SSCA, Oliveira TP, Cristo EB and Silva MMAD: Evolution of tobacco use indicators according to telephone surveys, 2006-2014. Cad Saude Publica 33 (Suppl 3): e00134915, 2017 (In English, Portuguese).

42. Azevedo e Silva G, Valente JG and Malta DC: Trends in smoking among the adult population in Brazilian capitals: A data analysis of telephone surveys from 2006 to 2009. Rev Bras Epidemiol 14 (Suppl 1): S103-S114, 2011 (In English, Portuguese)

43. Moura MA, Bergmann A, Aguiar SS and Thuler LC: The magnitude of the association between smoking and the risk of developing cancer in Brazil: A multicenter study. BMJ open 4: e003736, 2014

44. Bartholomay P, Iser BP, de Oliveira PP, dos Santos TE, Malta DC, Sobel $\mathrm{J}$ and de Moura L: Epidemiologic investigation of an occupational illness of tobacco harvesters in southern Brazil, a worldwide leader in tobacco production. Occup Environ Med 69: 514-518, 2012.

45. Opaleye ES, Sanchez ZM, Moura YG, Galduroz JC, Locatelli DP and Noto AR: The Brazilian smoker: A survey in the largest cities of Brazil. Braz J Psychiatry 34: 43-51, 2012.

46. Fiori NS, Faria NM, Meucci RD and Fassa AG: Smoking prevalence and associated factors among tobacco farmers in southern Brazil. Cad Saude Publica 32: S0102-311X2016000705012, 2016 (In Portuguese).

47. Munhoz TN, Santos IS, Nunes BP, Mola CL, Silva I and Matijasevich A: Trends in alcohol abuse in Brazilian state capitals from 2006 to 2013: An analysis of data from the VIGITEL survey. Cad Saude Publica 33: e00104516, 2017 (In Portuguese).

48. Munoz N, Victora CG, Crespi M, Saul C, Braga NM and Correa P: Hot mate drinking and precancerous lesions of the oesophagus: An endoscopic survey in Southern Brazil. Int J Cancer 39: 708-709, 1987.

49. Szymanska K, Matos E, Hung RJ, Wünsch-Filho V, Eluf-Neto J, Menezes A, Daudt AW, Brennan P and Boffetta P: Drinking of mate and the risk of cancers of the upper aerodigestive tract in Latin America: A case-control study. Cancer Causes Control 21: 1799-1806, 2010.

50. Mello FW, Scotti FM, Melo G, Warnakulasuriya S, Guerra ENS and Rivero ERC: Mate consumption association with upper aerodigestive tract cancers: A systematic review and meta-analysis. Oral Oncol 82: 37-47, 2018 
51. Putz A, Hartmann AA, Fontes PR, Alexandre CO, Silveira DA Klug SJ and Rabes HM: TP53 mutation pattern of esophageal squamous cell carcinomas in a high risk area (Southern Brazil): Role of life style factors. Int J Cancer 98: 99-105, 2002.

52. Castellsague X, Munoz N, De Stefani E, Victora CG, Castelletto R and Rolon PA: Influence of mate drinking, hot beverages and diet on esophageal cancer risk in South America. Int J Cancer 88: 658-664, 2000

53. Wunsch-Filho V: The epidemiology of oral and pharynx cancer in Brazil. Oral Oncol 38: 737-746, 2002.

54. Sans M: Admixture studies in Latin America: From the 20th to the 21st century. Hum Biol 72: 155-177, 2000.

55. Lins TC, Vieira RG, Abreu BS, Grattapaglia D and Pereira RW: Genetic composition of Brazilian population samples based on a set of twenty-eight ancestry informative SNPs. Am J Hum Biol 22: 187-192, 2010.

56. Saloum de Neves Manta F, Pereira R, Vianna R, Rodolfo Beutt enmüller de Araújo A, Leite Góes Gitaí D, Aparecida da Silva D, de Vargas Wolfgramm E, da Mota Pontes I, Ivan Aguiar J, Ozório Moraes M, et al: Revisiting the genetic ancestry of Brazilians using autosomal AIM-Indels. PLoS One 8: e75145, 2013.

57. Pena SD, Di Pietro G, Fuchshuber-Moraes M, Genro JP, Hutz MH, Kehdy Fde S, Kohlrausch F, Magno LA, Montenegro RC, Moraes MO, et al: The genomic ancestry of individuals from different geographical regions of Brazil is more uniform than expected. PLoS One 6: e17063, 2011.

58. Daly JM, Fry WA, Little AG, Winchester DP, McKee RF, Stewart AK and Fremgen AM: Esophageal cancer: Results of an American college of surgeons patient care evaluation study. J Am Coll Surg 190: 562-573, 2000

59. Dhillon PK, Farrow DC, Vaughan TL, Chow WH, Risch HA, Gammon MD, Mayne ST, Stanford JL, Schoenberg JB Ahsan $\mathrm{H}$, et al: Family history of cancer and risk of esophageal and gastric cancers in the United States. Int J Cancer 93: 148-152, 2001.
60. Tustumi F, Takeda FR, Kimura CM, Sallum RA, Ribeiro UJ and Cecconello I: Esophageal carcinoma: Is squamous cell carcinoma different disease compared to adenocarcinoma? a transversal study in a quaternary high volume hospital in Brazil. Arq Gastroenterol 53: 44-48, 2016.

61. Eslick GD: Epidemiology of esophageal cancer. Gastroenterol Clin North Am 38: 17-25, vii, 2009.

62. Napier KJ, Scheerer M and Misra S: Esophageal cancer: A Review of epidemiology, pathogenesis, staging workup and treatment modalities. World J Gastrointest Oncol 6: 112-120, 2014.

63. Bosetti C, Levi F, Ferlay J, Garavello W, Lucchini F, Bertuccio P, Negri E and La Vecchia C: Trends in oesophageal cancer incidence and mortality in Europe. Int J Cancer 122: 1118-1129, 2008.

64. Jemal A, Center MM, DeSantis C and Ward EM: Global patterns of cancer incidence and mortality rates and trends. Cancer Epidemiol Biomarkers Prev 19: 1893-1907, 2010.

65. Dikken JL, Dassen AE, Lemmens VE, Putter H, Krijnen P, van der Geest L, Bosscha K, Verheij M, van de Velde CJ and Wouters MW: Effect of hospital volume on postoperative mortality and survival after oesophageal and gastric cancer surgery in the Netherlands between 1989 and 2009. Eur J Cancer 48: 1004-1013, 2012.

66. Dikken JL, Lemmens VE, Wouters MW, Wijnhoven BP, Siersema PD, Nieuwenhuijzen GA, van Sandick JW, Cats A, Verheij M, Coebergh JW and van de Velde CJ: Increased incidence and survival for oesophageal cancer but not for gastric cardia cancer in the Netherlands. Eur J Cancer 48: 1624-1632, 2012. 